\title{
What are the immunological consequences of long-term use of biological therapies for juvenile idiopathic arthritis?
}

\author{
Joost F Swart*, Sytze de Roock and Nico M Wulffraat
}

\begin{abstract}
This review summarizes the immunological consequences of biological therapies used in juvenile idiopathic arthritis (JIA). For every frequently used biological agent the characteristics are clearly specified (molecular target, isotype, registered indication for JIA, route of administration, half-life, contraindication, very common side effects, expected time of response and average cost in the first year). The emphasis of this review is on the immunological side effects that have been encountered for every separate agent in JIA populations. For each agent these adverse events have been calculated as incidence per 100 patientyears for the following categories: serious infections, tuberculosis, malignancies, response to vaccination, new-onset autoimmune diseases and development of anti-drug antibodies. There are large differences in side effects between various agents and there is a clear need for an international and standardized collection of post-marketing surveillance data of biologicals in the vulnerable group of JIA patients. Such an international pharmacovigilance database, called Pharmachild, has now been started.
\end{abstract}

\section{Introduction}

Juvenile idiopathic arthritis (JIA) is the most common chronic rheumatic disease in children, with an incidence in Europe of about 16 to 150 per 100,000 per year, and an important cause of short-term and long-term disability [1]. The International League of Associations for Rheumatology has defined JIA as arthritis with no apparent cause lasting more than 6 weeks with disease onset prior to age 16 [2]. Seven different subtypes of JIA are

*Correspondence: jswart@umcutrecht.nl

Department of Pediatric Immunology and Rheumatology, Wilhelmina Children's Hospital/UMC Utrecht, PO Box 85090, 3508 AB Utrecht, The Netherlands recognized that differ in genetic susceptibility, distribution and severity of arthritis. One subtype, called systemic onset JIA (SIIA), representing 4 to $17 \%$ of all JIA cases, concerns a totally different disease entity in which innate immunity has been shown to be involved much more than adaptive immunity as seen in the other subtypes [1,3].

In the past 10 years the implementation of adequate legislation fostering controlled clinical trials in children and the availability of new potent medications such as the biologicals have led to a dramatic improvement in the treatment of systemic and non-systemic JIA [4]. A biologic medical product (biological or biologic) is a medicinal product that is produced by biologic processes rather than chemical synthesis. In 2011 an American College of Rheumatology recommendation published on the treatment of JIA mentioned six different biologicals: three types of TNF- $\alpha$ inhibitors (etanercept, adalimumab and infliximab), CTLA4-immunoglobulins (abatacept), anti-CD20-antibodies (rituximab) and an anti-IL1 receptor antagonist (anakinra) [5]. In fact, despite belonging to our standard of care, only half of these are registered for use in JIA (etanercept, adalimumab and abatacept). Another drug, an anti-IL6 receptor antibody (tocilizumab) has been registered for use in active SJIA by the US Food and Drug Administration (FDA) and several European countries in 2011. Long-acting antiIL1 $\beta$ antibodies (canakinumab) have recently been shown to be successful for treatment of SJIA [6].

For registration of a biological the efficacy on the specific indication has to be shown. However, safety issues other than very common adverse events can hardly be addressed in JIA studies since the study population would be too small and the follow-up mostly too short. Comparisons with placebo are of limited value in most of these studies because of the short duration of the placebo phase [7]. Moreover, a double-blind, controlled, randomized withdrawal design is used in nearly all randomized clinical trials for JIA therapy, where a control cohort never having used that drug is missing [8]. In this design eligible children are treated in an open-label fashion with 
the experimental therapy for a few months, after which responders are randomized in a double-blind fashion either to continue the experimental therapy or to switch to placebo [4]. Furthermore, the placebo-controlled phase is often shorter than the lead-in open-label phase, which could potentially introduce bias owing to latent adverse events initiated in the lead-in phase not being reported until the placebo-controlled phase [7].

\section{Clinical immunological consequences of long-term use of biologicals in JIA patients}

The features of the biologicals used in JIA are summarized in Table 1. Registered indications can differ between countries, and for this table we use the Dutch situation.

Clearly there are many immunologic differences between biologicals that act on varying targets, but even drugs that antagonize the same target - for example, TNF $\alpha$ - have been shown to differ quite a bit in this regard. The different origins and constructions of the anti-TNF agents infliximab, adalimumab and etanercept result in slightly different affinities and avidities for soluble TNFa. Nevertheless, all three have a high potency to bind TNF and form complexes $[9,10]$. These agents also bind to the membrane bound form of TNF $\alpha$ (mTNFa); however, only one molecule of etanercept binds to each trimer of $\mathrm{mTNF} \alpha$, while adalimumab and infliximab can bind with one molecule to each monomer of the mTNFo trimer [9-11]. Furthermore, the fact that etanercept is a fusion protein means that the first part of the constant region ( $\mathrm{CH} 1)$ of the antibody is absent; this part is important in the induction of complementdependent cytotoxicity or apoptosis of the cells to which the antibody is bound. Complement- 3 has to bind to the $\mathrm{CH} 1$ part of the antibody in order to form the membrane attack complex and absence of this results in a premature stop of the cascade. This suggests that only infliximab and adalimumab induce complement-dependent cytotoxicity. Indeed, in vitro experiments show this phenomenon for infliximab and adalimumab when cell lines are used that over-express mTNF $\alpha$ [12]. Nevertheless, when activated, untransformed peripheral blood monocytes were tested, no lysis was found with either adalimumab and infliximab, nor with etanercept, probably due to low expression of mTNF [9]. Another difference found between the agents is their capacity to induce immunosuppressive regulatory T-cell (Treg) populations. Induction of Tregs by monocyte-derived dendritic cells has been shown in the presence of adalimumab, but not with etanercept [13].

The half-lives of the different agents also reflect the necessary frequency of administration. Adalimumab has a half-life of 2 weeks and needs to be injected every 2 weeks, and anakinra with a half-life of 4 to 6 hours needs to be injected daily. However, the frequency of administration might change over time since etanercept, with a half-life of 70 hours, was meant originally to be injected twice weekly at a dose of $0.4 \mathrm{mg} / \mathrm{kg}$ body weight but it appeared to be as effective when administered once weekly at a dose of $0.8 \mathrm{mg} / \mathrm{kg}[14,15]$.

Contraindications involve mainly serious active infections, more specifically tuberculosis (TB) in the setting of anti-TNF therapy. Furthermore, heart failure is a contraindication for several anti-TNF-agents. Hypersensitivity to xenogenic proteins may constitute a contraindication for use of chimeric biologicals. In case of a previous diagnosis of cancer, it might be wise to refrain from antiTNF-therapy until further data appear.

Very common side effects - those affecting more than $10 \%$ of patients - are different for every agent but mostly concern (upper) respiratory tract infection, headache and injection site reaction.

The expected time of response is normally within 3 to 4 months, which should be the time to consider a change of therapy if no beneficial response is seen. For anakinra and canakinumab the effect in SJIA is much swifter and is expected to occur within days.

The average cost per year is calculated for a $30 \mathrm{~kg}$ (66 lb) child in 2010 purchase price (excluding VAT) for pharmacies in the Netherlands. The content per vial is usually too high to administer to a typical JIA patient with the low bodyweight that (young) children normally have and, therefore, much of the material must be discarded. In the Netherlands only four out of these ten biologicals (abatacept, etanercept, rituximab and tocilizumab) have vials that prevent annual spillage of thousands of euros per pediatric patient.

Since biologicals antagonize cytokines or receptors involved in the immune system, one could fear that their (long-term) use might affect the quality of the immune system, leading to a defective defense mechanism against infections and tumors, an insufficient response to vaccinations, or a flawed immunoregulation resulting in autoimmunity or autoinflammation (Table 2). Finally, a biological agent itself can be handled as an antigen by the immune system, producing antibodies against the biological.

\section{Serious infections}

The recombinant therapeutic proteins directed against molecules of the immune system could induce infections in JIA patients treated with these biologicals that may display some similarities to those in patients with primary immunodeficiency of the corresponding biologic target [16]. Therefore, some side effects may be foreseen by analyzing primary immunodeficiency [16].

For most of the trials reviewed, 'serious bacterial infections' are defined as those requiring antibiotics or hospitalization. Biologicals (for example, anakinra and 


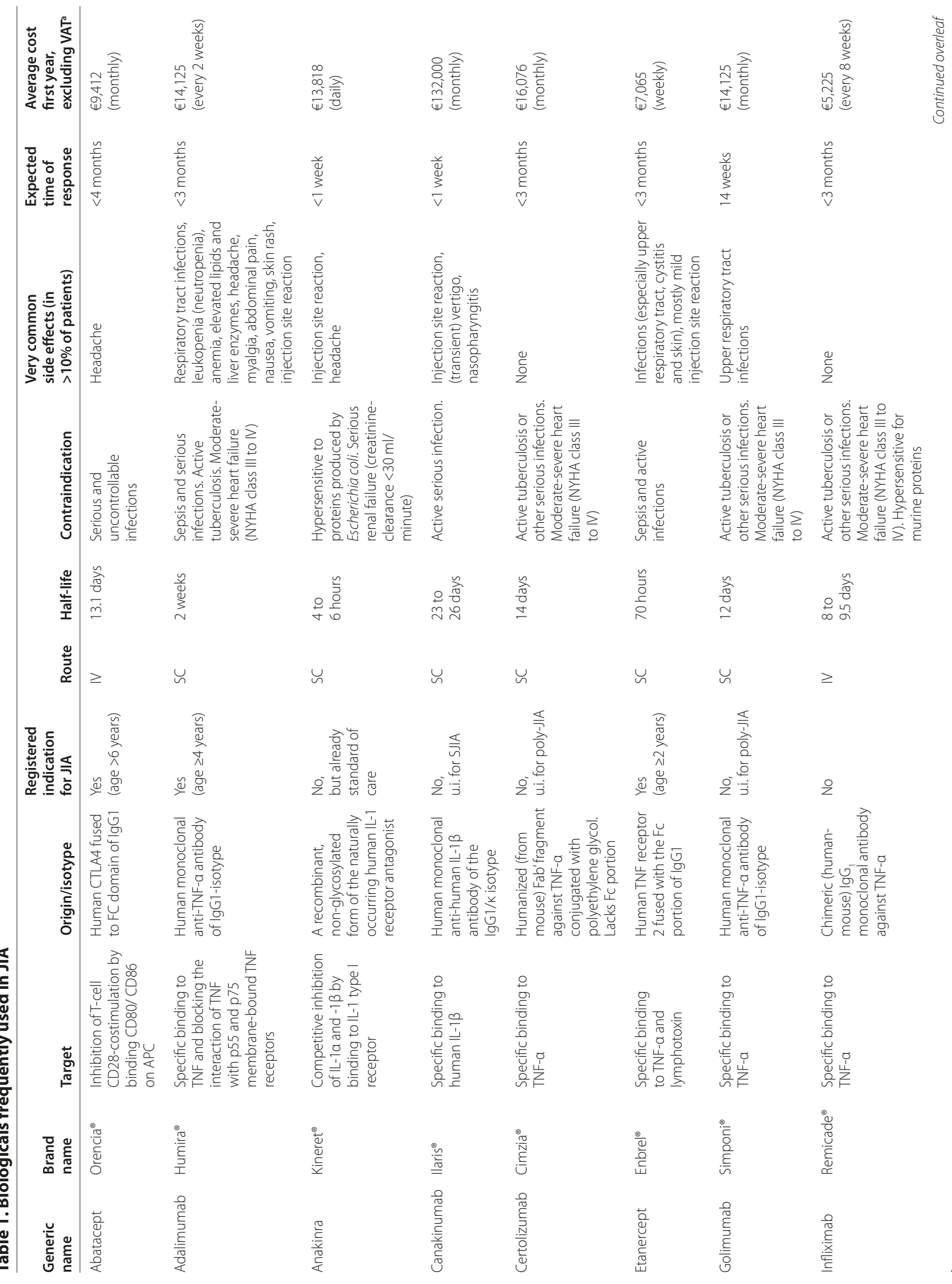




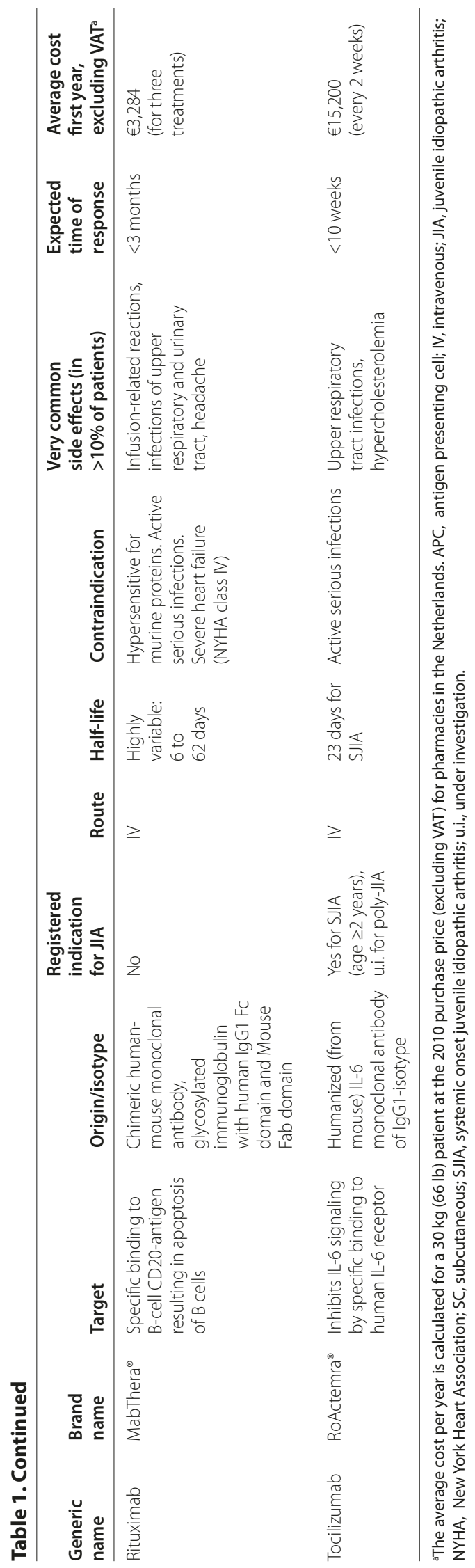

tocilizumab) and high-dose corticosteroids may affect body temperature (no fever) and acute phase reactions (low C-reactive protein and erythrocyte sedimentation rate) and some biologicals may induce neutropenia instead of leukocytosis. Therefore, one should be cautious when using these parameters to diagnose an infection in the setting of these agents.

For the background rate of serious infections in JIA patients with and without (biological) drug use, one study compared during a median follow-up of 1.2 years 8,479 JIA patients with 360,489 children diagnosed with attention deficit hyperactivity disorder (ADHD) [17]. Overall, the crude infection rate was 2.8 per 100 personyears and nearly three-fold higher among children diagnosed as having JIA than among children diagnosed as having $\mathrm{ADHD}$ (1.0 per 100 person-years). Even in children with JIA who were not currently being treated with steroids, methotrexate (MTX) or TNF inhibitors, a two-fold increase was found in the rates of hospitalized bacterial infections compared to children without JIA. This finding suggests that the inflammatory process of JIA itself may predispose children to infection irrespective of therapy [17]. It is not known whether any subtype of JIA (for example, SJIA) makes children even more prone to infection. The risk of infection increased a further three-fold with the use of high-dose glucocorticoids, but was not significantly increased with MTX use [17].

Opportunistic infections were found in 42 instances in a JIA cohort consisting of 8,503 children with 13,990 person-years of follow-up. Therefore, the incidence rate of opportunistic infections in JIA was 0.3 per 100 patientyears, which was an increased risk of 2.4 compared to the ADHD comparator cohort of 360,362 children with 477,050 patient-years of follow-up [18]. The most common opportunistic infections among children with JIA were three Coccidioides, five Salmonella and 32 herpes zoster [18]. There was no marked association between specific immunosuppressant medication use and herpes zoster, although the precision of the estimates was limited by the relatively small number of observed infections. In addition, none of the three children with JIA and incident Coccidioides infections were exposed to anti-TNF agents during the study period [18].

\section{Abatacept}

During the open-label extension phase, the largest abatacept-study for JIA patients found 1.33 serious infections per 100 patient-years among 153 JIA patients using abatacept with median treatment duration of 2.9 years [19]. In 74\% of patients there was concomitant use of MTX at a mean dosage of $13.2 \mathrm{mg} / \mathrm{m}^{2} /$ week. Five patients experienced six serious infections (one each of dengue fever, erysipelas, gastroenteritis, herpes zoster, bacterial meningitis, and pyelonephritis) [19]. 
Table 2. Immunological consequences of biologicals in juvenile idiopathic arthritis: incidence rates per 100 patient-years (weighted per study)

\begin{tabular}{|c|c|c|c|c|}
\hline Generic name & $\begin{array}{l}\text { Serious } \\
\text { infections }\end{array}$ & Malignancies & Autoimmune disease $^{a}$ & Antibody formation \\
\hline \multirow{4}{*}{$\begin{array}{l}\text { Normal childhood } \\
\text { population }\end{array}$} & \multirow[t]{4}{*}{$1.0[17]$} & \multirow[t]{4}{*}{$0.032[53,54,56]$} & 0.0069 new onset uveitis [77] & \multirow[t]{4}{*}{-} \\
\hline & & & 0.0083 IBD [78] & \\
\hline & & & 0.00015 optic neuritis [79] & \\
\hline & & & 0,0001 multiple sclerosis [80] & \\
\hline $\begin{array}{l}\text { JA without MTX, } \\
\text { steroids or anti-TNF }\end{array}$ & $2.2[17]$ & $0.025[53,56]$ & 2.5 new onset uveitis $[81,82]$ & - \\
\hline JIA with MTX & $3.3[17]$ & $\begin{array}{l}0.033[56] \text { to } \\
0.046^{c}[54]\end{array}$ & 0.83 uveitis [83] & - \\
\hline JIA with steroids & $6.9[17]$ & No data & No data & - \\
\hline \multirow[t]{2}{*}{ Abatacept } & \multirow[t]{2}{*}{$1.3[57]$} & \multirow[t]{2}{*}{ No data } & 0.22 uveitis flare (1 per $448 \mathrm{EY}$ ) [19] & \multirow[t]{2}{*}{23 (no adverse events) [57] } \\
\hline & & & 0.22 multiple sclerosis (1 per 448 EY) [19] & \\
\hline \multirow[t]{2}{*}{ Adalimumab } & \multirow[t]{2}{*}{$2.9[28-30]$} & \multirow[t]{2}{*}{ No data } & \multirow[t]{2}{*}{$\begin{array}{l}0 \text { demyelinating diseases ( } 0 \text { per } 348 \mathrm{EY} \text { ) } \\
{[28,30]}\end{array}$} & $\begin{array}{l}7.6 \text { with MTX within year; } 15 \text { after first year } \\
\text { (no adverse events) [28,30] }\end{array}$ \\
\hline & & & & $\begin{array}{l}25.3 \text { without MTX within first year; } 60 \text { after } \\
\text { first year (no adverse events) [28,30] }\end{array}$ \\
\hline \multirow[t]{2}{*}{ Anakinra } & \multirow[t]{2}{*}{$8.7[20-22]$} & \multirow[t]{2}{*}{ No data } & \multirow[t]{2}{*}{ No data } & $\begin{array}{l}75.0 \text { non-neutralizing antibodies within } \\
\text { first year; } 81.8 \text { after first year [73] }\end{array}$ \\
\hline & & & & $\begin{array}{l}6.3 \text { neutralizing antibodies within first year; } \\
0 \text { after first year [ } 73]\end{array}$ \\
\hline \multirow[t]{5}{*}{ Etanercept } & \multirow[t]{5}{*}{$2.7[17,31-34]$} & \multirow[t]{5}{*}{$0.015[59]$} & $\begin{array}{l}0.44 \text { new onset uveitis }[32,34] \text { and } \\
0.57 \text { flares of uveitis }[33,35]\end{array}$ & \multirow[t]{5}{*}{2.9 non-neutralizing antibodies [74] } \\
\hline & & & 0.31 newly diagnosed IBD $[35,70]$ & \\
\hline & & & 0.15 optic neuritis [31-35] & \\
\hline & & & 0.11 new onset lupus $[31,34,35]$ & \\
\hline & & & 0.64 newly diagnosed sarcoidosis [32] & \\
\hline \multirow[t]{3}{*}{ Infliximab } & \multirow[t]{3}{*}{$1.0[36,37]$} & \multirow[t]{3}{*}{ No data } & 5.1 new onset uveitis [36] & \multirow{3}{*}{$\begin{array}{l}36.6 \text { positive and } 32.4 \text { inconclusive } \\
\text { (infusion-reaction-related) [36] }\end{array}$} \\
\hline & & & $\begin{array}{l}25.9 \text { new ANA ( } \geq 1: 320) \text { without } \\
\text { symptoms [36] }\end{array}$ & \\
\hline & & & $\begin{array}{l}6.6 \text { new anti-double-stranded DNA } \\
\text { antibodies without symptoms [36] }\end{array}$ & \\
\hline Rituximab & $14.5^{\mathrm{d}}[24]$ & No data & No data & No data \\
\hline Tocilizumab & $11.6^{e}[38-40]$ & No data & No data & $\begin{array}{l}7.1 \text { (one anaphylactoid reaction without anti-lgE } \\
\text { antibody) [38] }\end{array}$ \\
\hline
\end{tabular}

${ }^{a}$ Only mentioned if at least 100 exposure years (EY) available. bMajority of these patients did not use MTX, steroids or anti-TNF agents. This study used biologic naïve


concomitantly used steroids. EY, exposure years; IBD, inflammatory bowel disease; JIA, juvenile idiopathic arthritis; MTX, methotrexate.

\section{Anakinra}

Three out of 45 patients with SJIA treated with anakinra for a median duration of 1.1 years developed a serious infection, resulting in 6.1 per 100 patient-years [20]. Two of these three explicitly used steroids as well and all three could safely restart anakinra after clearance of infection [20]. Corticosteroids were used at an initial dose of $0.6 \mathrm{mg} /$ $\mathrm{kg} /$ day in $67 \%$ of all the study patients and $33 \%$ of patients also used other disease-modifying anti-rheumatic drugs
(DMARDs), while only $22 \%$ of patients used anakinra monotherapy [20]. Another study documented 32 SJIA patients taking anakinra for a median duration of 0.5 years with $84 \%$ using steroids and $85 \%$ also nonbiological DMARDs at the start of anakinra without observing serious infections [21]. A third study involved 24 SJIA patients who were treated with anakinra for 1 year concomitant with a rather high dose of steroids ( 0.5 to $0.6 \mathrm{mg} / \mathrm{kg} /$ day) and found that 4 patients developed 
a serious infection during 15.2 patient-years of follow-up, resulting in 26.4 serious infections per 100 patient-years [22]. Monotherapy anakinra, however, seems much safer, since in our own center we did not experience any serious infection in 24 new-onset SJIA patients treated with monotherapy anakinra [23].

\section{Rituximab}

Serious infections were seen in 14.5 per 100 children (pneumonia) in 55 children with JIA (46 with SJIA) who were treated with rituximab administered as weekly intravenous infusion for 4 successive weeks $(375 \mathrm{mg} / \mathrm{m} 2$ per dose) [24]. Because of efficacy, intolerance or inefficacy, only 25 patients received all 4 courses, 41 received 3 courses and 44 patients received 2 courses. MTX was taken by $100 \%$ concomitantly at a mean weekly dose of $16.4 \mathrm{mg} / \mathrm{m}^{2} ; 87 \%$ also used cyclosporine $(4 \mathrm{mg} /$ $\mathrm{kg} /$ day $)$ and $45 \%$ even used prednisolone $(0.3 \mathrm{mg} / \mathrm{kg} /$ day). The pneumonias were caused in $62 \%$ by Pneumocystis jirovecii and associated pneumocystic and mycoplasma infections [24]. Since multiple drugs were taken, it is hard to discriminate which adverse effect was caused by rituximab per se.

For rheumatoid arthritis (RA) the overall serious infection rate was 4.31 per 100 patient-years [25]. Infections and serious infections over time remained stable across 5 courses at 4 to 6 events per 100 patient-years. Four cases of the often fatal progressive multifocal leukoencephalopathy (PML) caused by the JC virus in patients with RA treated with rituximab have been reported [26]. This would be equivalent to an incidence of one case of PML per 25,000 individuals with RA being treated with rituximab [26]. A recent study, using a Freedom of Information Act request for all cases of PML within the Food and Drug Administration (FDA) Adverse Event Reporting System database, selected autoimmune rheumatic diseases for further analysis [27]. They found a specific signal emerging with regard to rituximab and PML; although this is a rare adverse event associated with rituximab therapy, the devastating nature of PML mandates continued vigilance, particularly in patients with current or prior exposure to an alkylating agent [27].

\section{TNF inhibitors}

\section{Adalimumab}

Serious infections (pneumonia and severe viral infections) were observed in 2.2 per 100 exposure years during 319 adalimumab exposure years [28]. Another study found serious infections in 2.8 per 100 patient-years or 2 of the 26 JIA patients with 71.6 patient-years of adalimumab exposure (fatal sepsis and severe skin abscesses requiring surgery) [29]. In a third study serious infections were seen in 11.1 per 100 exposure years or 3 of 25 (mainly rheumatoid factor-positive) JIA patients with an average duration of adalimumab of 1.1 years (acute pharyngitis, pneumonia, and hepatitis B infection) [30].

\section{Etanercept}

No increase in hospitalized infections was seen in the $16 \%$ of 8,479 JIA patients using a TNF inhibitor $(90 \%$ etanercept) compared to JIA patients without medication or with MTX for over a year [17]. The incidence of hospitalized infections in this anti-TNF group was 3.5 per 100 patient-years, but doubled when there was concurrent use of corticosteroids [17]. The most common hospitalized infections seen in that study were upper respiratory tract $(30 \%)$, pneumonia $(24 \%)$, bacteremia/ septicemia (18\%), urinary tract/pyelonephritis (18\%), and skin and soft tissue (12\%). In an open-label extension study of etanercept in JIA patients, serious infections were seen in 3 per 100 patient-years among the 58 patients with 318 patient-years of etanercept exposure [31]. The exposure-adjusted rates of infections that led to hospitalization or treatment with intravenous antibiotics remained low over the period of study [31]. Another study found only 1.2 cases per 100 patient-years or 4 serious infections during 312 patient-years of etanercept use in JIA patients ( 3 cases with gastroenteritis and 1 urosepsis) [32]. A German study reported 3.2 serious infections per 100 patient-years or 26 infectious serious adverse events occurring in 604 etanercept-using JIA patients with 1,149 patient-exposure years [33]. Another German biologic register found 2.1 severe infections per 100 patient-years in 346 JIA patients ever on etanercept (45\% still using) during the observation period comprising 598 patient-years [34]. Permanent discontinuation of etanercept because of serious infection (Epstein-Barr meningoencephalitis, pyelonephritis, recurrent urinary tract infection, gingival infection, sepsis) was noted in only 5 JIA patients during 941 patient-years [35].

\section{Infliximab}

In an open-label extension study, an occurrence of pneumonia of 1.2 per 100 patient-years was reported as it was seen in 2 out of 78 JIA patients receiving initially $3 \mathrm{mg} / \mathrm{kg}$ infliximab plus MTX during 2.2 years of average follow-up [36]. A smaller study with 20 JIA patients taking infliximab plus MTX during one year showed no infections requiring hospitalizations [37].

\section{Tocilizumab}

A serious infection risk of 9.3 per 100 patient-years for tocilizumab in SJIA with concomitant steroid use was seen [38]. Two cases of bronchitis and two cases of gastroenteritis were considered to have serious adverse events in 48 SJIA patients using both 2-weekly $8 \mathrm{mg} / \mathrm{kg}$ tocilizumab and prednisolone at a dose of 0.4 to $0.5 \mathrm{mg} /$ $\mathrm{kg} /$ day during a 0.9 year open-label extension study [38]. 
Another study found a serious infection risk of 11 per 100 patient-years during a 0.23 year double-blind phase ( 2 events in 75 SJIA patients randomized to tocilizumab) versus no serious infections in the 37 patients receiving placebo [39]. The same serious infection risk of 11 per 100 patient-years was found in the 112 SJIA patients with a median tocilizumab exposure of 1.4 year [39].

For polyarticular JIA, a serious infection risk of 19.6 per 100 patient-years was found in 17 JIA patients (half of them rheumatoid factor-positive) followed for 0.9 years using monthly $8 \mathrm{mg} / \mathrm{kg}$ tocilizumab [40]. During the study period, no patient was withdrawn due to adverse events, but three patients required hospitalization because of serious infectious events (two cases of gastroenteritis and one case of pneumonia) [40].

The downregulatory effect of tocilizumab on the acutephase reactant C-reactive protein may limit the usefulness of C-reactive protein as a diagnostic indicator for infections. Tocilizumab should not be given in the presence of serious or opportunistic infections [41].

\section{Tuberculosis}

Soon after a report showing that active and even disseminated tuberculosis (TB) developed in 48 patients after three or fewer infusions of infliximab even in countries with low incidence of tuberculosis, it was realized that TNF inhibitors should not be given to patients with latent TB infection (LTBI) [42]. Indeed, for JIA patients the same risk applies, as was shown by the report of a fatal extra-pulmonary TB infection in a SJIA patient who was treated with infliximab [43]. Testing for LTBI is now a prerequisite before a TNF inhibitor can be started. However, the tuberculin skin test (TST), measuring the Th1 cell-type response to purified protein derivative, is significantly lower in bacillus CalmetteGuerin (BCG)-vaccinated children with JIA compared to healthy children [44]. These results show that the purified protein derivative response that has been used for years in screening for TB will not be accurately informative in cases of JIA; these therefore would require the application of more sensitive tests [44]. A Mycobacterium tuberculosis-specific interferon gamma enzyme-linked immunosorbent assay (IGRA) is not affected by BCG vaccination, but it was not known if it is affected by the illness itself or the immunosuppressive drugs used. Such an IGRA test, the QuantiFERON-TB Gold In-Tube, was therefore compared with the TST for detection of latent tuberculosis infection in patients with JIA in a cross-sectional study of 39 children with JIA and 40 healthy controls in İzmir, Turkey [45]. Also in this study the median TST induration was significantly lower for the JIA group $(5.8 \mathrm{~mm})$ than for the control group $(10.7 \mathrm{~mm})$. The rate of patients who, despite BCG, showed no reaction to TST $(0 \mathrm{~mm})$ was $38 \%$, of which $93 \%$ had active JIA [45].
Overall agreement between TST and IGRA was low in both the JIA and control group. The IGRA may be useful to identify false negative TST response in cases with latent $M$. tuberculosis infection, since there were two patients who had positive IGRA $(\geq 0.35 \mathrm{IU} / \mathrm{ml})$ but negative TST results $(<10 \mathrm{~mm})$ [45]. The usefulness of TST and IGRA for monitoring TB during anti-TNF treatment has been shown as well, since treatment with TNF- $\alpha$ antagonists did not cause a significant change in the TST or IGRA positivity rate [46]. For JIA patients there are no specific guidelines for TB screening or monitoring when starting biologicals but in 2012 an update of the 2008 American College of Rheumatology recommendations for the use of DMARDs and biologic agents in the treatment of RA was published, which can be used for JIA patients as well [47]. The panel recommends the TST or IGRA as the initial test in all RA patients starting biologic agents, regardless of risk factors for LTBI. It recommends the use of the IGRA over the TST in patients who have previously received a BCG vaccination, due to the high false positive test rates for the TST. The panel recommends that RA patients with a positive initial or repeat TST or IGRA should have a chest radiograph and, if suggestive of active TB, a subsequent sputum examination to check for the presence of active TB. RA patients with a negative screening TST or IGRA may not need further evaluation in the absence of risk factors (Centers for Disease Control list) and/or clinical suspicion for TB. Since patients with RA may have false negative TST or IGRA results due to immunosuppression, a negative TST or IGRA should not be interpreted as excluding the possibility that a patient has LTBI. Accordingly, in immunosuppressed RA patients with risk factors for LTBI and negative initial screening tests, the panel recommends that a repeat TST or IGRA could be considered 1 to 3 weeks after the initial negative screening. The panel recommends annual testing in RA patients who live, travel, or work in situations where TB exposure is likely while they continue treatment with biologic agents. Patients who test positive for TST or IGRA at baseline can remain positive for these tests even after successful treatment of TB. These patients need monitoring for clinical signs and symptoms of recurrent $\mathrm{TB}$, since repeating tests will not help in the diagnosis of recurrent $\mathrm{TB}$ [47].

\section{Abatacept}

There were no reports of tuberculosis during the 448 exposure years in 153 JIA patients using abatacept who were pre-screened for TB [19].

\section{Anakinra}

No TB cases have been described in JIA patients using anakinra. To date, there is no indication that use of 
anakinra is associated with an increased incidence of TB [48].

\section{Rituximab}

No TB cases have been described in JIA patients using rituximab. There is no evidence of an increased incidence of TB in patients with non-Hodgkin lymphoma treated with rituximab. There are insufficient data to make a determination about the necessity to screen for TB before starting treatment [48].

\section{TNF inhibitors}

No cases of TB were reported during studies with JIA patients, who were pre-screened and did not have active or untreated LTBI, using adalimumab [28,29] or etanercept [31]. For infliximab therapy, despite negative TST screening at baseline, one patient was diagnosed with asymptomatic TB (pulmonary infiltration, TST of $13 \mathrm{~mm}$ and polymerase chain reaction test of a sputum sample that was positive for Mycobacterium tuberculosis complex) following routine repeat screening at week 108 [49]. This patient had resolution of the interstitial infiltrates as well as negative follow-up skin test results following quadruple anti-TB therapy and cessation of infliximab therapy.

\section{Tocilizumab}

No TB was seen in 65 SJIA using tocilizumab during 0.9 years, nor in 112 SJIA patients during 1.4 years who were all prescreened to not have LTBI or active TB before the start of tocilizumab [38-40].

\section{Malignancies}

Between 2001 and 2008, the FDA received reports of 48 malignancies occurring in children and adolescents exposed to TNF blockers (31 infliximab, 15 etanercept, 2 adalimumab), of which 15 occurred in patients aged younger than 18 years with JIA [50]. It was suggested that an elevated rate of malignancy, particularly lymphoproliferative cancers, was observed in patients with JIA treated with TNF antagonists, which led to a black box warning for these drugs by the FDA [51].

To appreciate the additional risk of a drug, however, it is necessary to know the background rate of malignancies in patients with JIA and the role of other immunosuppressants they are taking (for example, MTX). Indeed, all five cases of malignancies that were documented from 2001 to 2009 in the German JIA biologics registry (covering 1,260 patients at the time) had been exposed to a number of cytostatic and cytotoxic drugs, including MTX, leflunomide, azathioprine and ciclosporin-A, before institution of TNF- $\alpha$ blockers [52]. Three studies have investigated the background rate of malignancy in JIA patients. The cancer occurrence at three Canadian pediatric rheumatology centers was studied by linking the subjects of JIA registries to regional tumor registries in order to determine the occurrence of invasive cancers over the observation period (spanning 1974 to 2006) [53]. The study sample consisted of 1,834 JIA patients (majority Caucasian females) observed for an average of 12.2 years. Only 0.0045 cancers per 100 patient-years were found (1 Hodgkin's lymphoma in 22,341 patientyears) compared to 0.031 per 100 patient-years ( 7.9 cases expected), which leads to a protective standardized incidence ratio (SIR) of 0.12 (95\% confidence interval (CI) 0.0 to 0.70) [53]. In Sweden, through linkage with the Swedish Patient Register, a national JIA cohort $(n=9,027)$ was identified and each JIA case was matched with five general population comparators [54]. This biologics-naive JIA cohort included 0.046 cases per 100 person-years (60 malignancies observed during 131,144 person-years of follow-up) versus 0.040 cases per 100 person-years in the general population. Patients with JIA identified before 1987 were not at increased risk of cancer, whereas JIA identified in 1987 and thereafter was significantly associated with incident lymphoproliferative malignancies (relative risk 4.2, 95\% CI 1.7 to 10.7 ) and cancers overall (relative risk $2.3,95 \%$ CI 1.2 to 4.4). This increased risk was not explained by the introduction of biologic therapies, since the association was similar in analyses ending in 1999 when biologics became available, but it is important to note that in 1986 the first report was published of MTX use in JIA [55,56]. Another study also found an increased risk for malignancies in JIA patients without biologicals using national Medicaid data from 2000 through 2005 [56]. The JIA cohort included 7,812 children with a total follow-up time of 12,614 person-years and the referent group included 321,821 children with ADHD with 391,984 person-years of follow-up [56]. Probable and highly probable malignancies occurred in 0.055 per 100 person-years among JIA children compared to 0.013 per 100 person-years for the comparator group, leading to a significantly increased SIR of 4.4 (95\% CI 1.8 to 9.0). For those taking MTX without TNF inhibitor use, the SIR was 3.9 (95\% CI 0.4 to 14 ). It should be noted, however, that the rate of incidence of malignancies in the comparator ADHD group was much lower than that seen in the other studies [56].

\section{Abatacept}

One acute lymphoblastic leukaemia was diagnosed on day 89 in a randomized controlled trial of abatacept in polyarticular JIA [57]. This patient had been anemic at enrolment, with progressively decreasing hemoglobin concentrations as early as day 19 [57].

\section{Adalimumab}

No malignancies were reported in JIA clinical trials encompassing over 6 years of adalimumab exposure [58]. 


\section{Etanercept}

In the USA, 0.015 malignancy cases per 100 etanercept exposure-years were confirmed in patients aged 4 to 17 years (5 cases among 33,409 exposure years) [59]. In another USA JIA cohort including 1,484 JIA children and 2,922 person-years of TNF inhibitor exposure $(90 \%$ etanercept) no probable or highly probable malignancies were identified [56].

\section{Rituximab}

There is no evidence that rituximab is associated with an increased incidence of solid tumors in RA [48].

\section{Tocilizumab}

No malignancies were seen in 65 JIA patients using tocilizumab followed for 0.9 years, nor in the 112 SJIA patients followed for 1.4 years [38-40].

\section{Vaccination}

Recently, European League Against Rheumatism recommendations for safe and efficacious vaccination in pediatric patients with rheumatic diseases have been published [60]. Generally, the immunogenicity of vaccines is good in JIA patients. There are some exceptions, depending on the type and dose of immunosuppressive treatment and the type of vaccine [60].

Non-live vaccines seem to be safe while using glucocorticosteroids (2.5 to $40 \mathrm{mg} /$ day), MTX 7 to $25 \mathrm{mg} /$ week, other DMARDs such as azathioprine, or biological agents. However, MTX reduces responses to T-cell-independent polysaccharide pneumococcal vaccine, while Tcell-dependent responses to conjugate vaccines are good [60].

Limited data so far indicate that live attenuated booster vaccines are safe in patients on regular MTX dosages, low-dose glucocorticosteroids and anti-TNF $\alpha$ therapy. No increase in disease activity or medication use was seen in the 6 months after measles, mumps and rubella (MMR) booster vaccination in 207 JIA patients, including in patients using MTX $(n=49)$ [61]. In patients on highdose immunosuppressive drugs and biological agents, live attenuated vaccines, especially booster vaccinations, are not contraindicated, but no firm conclusions on safety in these patients can be drawn. Responses to various vaccines (VZV) were reduced in patients on high-dose glucocorticosteroids or azathioprine, while the responses to live-attenuated vaccines are good in JIA patients using MTX [60]. Primary vaccines are generally administered before the onset of rheumatic diseases, and booster vaccines may be administered when essential with or without temporary discontinuation of certain immunosuppressants [60]. In patients on high-dose immunosuppressants or biologicals, one should individually weigh the risk of primo-infection (unvaccinated exposure), the possible side effects of live-attenuated vaccination during medication and the risk of disease exacerbation during temporary withholding of immunosuppressants.

\section{Abatacept}

There are no data on the immunogenicity and adverse effects of vaccination in JIA patients using abatacept.

\section{Anakinra}

One child receiving corticosteroids and anakinra at $1.4 \mathrm{mg} / \mathrm{kg} /$ day inadvertently received the live MMR vaccine without evident harm [20]. Patients who were naive for anti-pneumococcal immunization received 23-valent pneumococcal polysaccharide immunization on the first day of anakinra treatment in order to assess the effect of anakinra treatment on anti-pneumococcal antibody response to five capsular polysaccharides at 1 and 12 months [22]. At 1 month the levels of postvaccination antibodies against five pneumococcal capsular polysaccharide serotypes were not significantly different between the anakinra- or placebo-treated patients. At 12 months 11 of the 12 anakinra-treated patients adequately responded to all serotypes and the 12th patient had a normal response to 3 of the 5 serotypes [22].

\section{Rituximab}

There are no data on the immunogenicity and adverse effects of vaccination in JIA patients using rituximab. However, it is known that rituximab significantly decreased the immune response to neoantigen and pneumococcus as well as to flu vaccination, whereas responses to tetanus and delayed-type hypersensitivity responses were unchanged [62]. After rituximab administration, humoral responses to flu vaccination were modestly restored at 6 to 10 months. It is recommended that any vaccinations required by the patient, such as those to prevent pneumonia and flu, should be given before the start of treatment [63]. The use of live attenuated vaccines should only be given before the use of rituximab until further data are available.

\section{TNF inhibitors}

The immunogenicity of the attenuated live vaccine against MMR was tested in five JIA patients treated with etanercept compared to 22 healthy children [64]. Etanercept treatment given simultaneously with revaccination did not interfere markedly with generation of long-lived virus-restricted $\mathrm{T}$ cells and protective levels of virus-specific IgG antibodies [64]. No increase in disease activity or medication use was seen within 6 months after MMR revaccination [64]. A larger study examined the immunogenicity and safety of two doses of 7-valent conjugate pneumococcal vaccine in 31 JIA patients with 
median age 12.9 years treated with anti-TNF agents plus DMARDs and 32 age-matched children treated only with DMARDs [65]. After the first vaccine dose, geometric mean titers (GMTs) were significantly increased for all vaccine serotypes $(P<0.0001)$ in both groups and were found to be protective in 87 to $100 \%$ of all children, depending on the serotype. A four-fold or more increase of the baseline titers to five or more vaccine serotypes was observed in $50 \%$ of the anti-TNF-treated and in 75\% of the control patients $(P=0.0697)$. Children receiving anti-TNFs achieved significantly lower GMTs against serotypes 4,14 and 23F $(P<0.05)$. No patient developed vaccine-associated serious adverse events or disease flares [65]. The MF-59 adjuvanted seasonal influenza vaccine was evaluated for immunogenicity, safety, and tolerability in 60 pediatric patients with JIA (30 treated with etanercept and 30 with DMARDs) compared to 30 healthy controls of similar gender and age [66]. The JIA patients treated with etanercept showed significantly lower GMTs against the $\mathrm{A} / \mathrm{H} 1 \mathrm{~N} 1$ strain than those treated with DMARDs $(P<0.05)$ and the healthy controls $(P<0.05)$, who had similar GMTs. Furthermore, the seroconversion and seroprotection rates were all significantly lower in JIA patients treated with etanercept than those of the subjects in the other two groups $(P<0.05)$. The safety and tolerability of the vaccine were good and similar between the groups [66]. Another study, however, showed normal seroconversion and seroprotection rates 21 days after vaccination against the H1N1 influenza virus in the 16 patients using anti-TNF therapy and these were significantly higher than in the 79 patients not using antiTNF agents [67]. Regarding vaccine safety, no deterioration was observed in the number of active joints and acute phase reactants during the study period [67].

\section{Tocilizumab}

The efficacy of influenza vaccination did not differ significantly between the 27 patients in the SJIA group and the 17 healthy controls [68]. The duration of tocilizumab administration did not affect the response of the sJIA patients to the influenza vaccination. None of the sJIA patients experienced either severe adverse reactions or disease exacerbation after the influenza vaccination [68].

\section{Autoimmune disease}

The development of new autoimmune diseases while using biological response modifiers could be the surfacing of an already underlying or associated disease entity. Uveitis, for example, is a common complication of JIA and in $1.3 \%$ of patients with Crohn's disease the chronic arthritis was prevalent before the diagnosis of the intestinal disease was made [69]. However, it could also be a new association now seen with the use of biologicals. Indeed, multiple reports of demyelinating diseases developing in patients using anti-TNF agents appeared, which in 2010 led to an update in the Warnings and Precautions section of the labeling of all of the TNF blockers to include peripheral demyelinating neuropathies. So far data are not sufficiently compelling to recommend screening for certain autoimmune diseases in JIA patients on specific biologicals, although the occurrence of new symptoms should make one consider a newly developed autoimmune disease.

\section{Abatacept}

Uveitis was reported in only 0.22 patients per 100 patient-years (1 case during 448 exposure years of abatacept, which resolved with topical prednisone without a need to discontinue abatacept) [19]. Multiple sclerosis developed in a 12-year-old boy on day 593 and he discontinued abatacept treatment [19].

\section{Adalimumab}

No demyelinating diseases or lupus-like reactions were reported during a study with 319 adalimumab exposure years in JIA patients [20]. Another study did not find any development of persistent new autoantibodies in the sequential immunology work-up during 71.6 patientyears of adalimumab [29]. Also, a third study found no demyelinating disease, allergic reactions or lupus-like syndrome after 29 exposure years [30].

\section{Anakinra}

One patient with SJIA using anakinra for over 1 month was diagnosed as having Morbus Crohn [22]. The diagnosis of SJIA is one by exclusion of other diagnoses and it is very well known that inflammatory bowel diseases (IBDs) can simulate SJIA with fever and arthritis. Therefore, it is not sure whether this case with IBD can be attributed to anakinra or just surfaced under anakinra treatment.

\section{Etanercept}

The IBD incidence in JIA patients while using etanercept was 0.36 per 100 patient-years under etanercept, about 43 times higher than in the general pediatric population [70]. The time between the start of etanercept and the first appearance of IBD symptoms was between 9 days and 4.5 years [70]. During 941 JIA patient-years with etanercept use in 483 patients, IBD-associated arthritis was found in 0.11 per 100 patient-years [35]. Uveitis flare and optic neuritis were found with the same incidences in that study [35]. In an open-label extension study of etanercept in JIA patients no cases of demyelinating disorders or lupus were observed in 58 patients with 318 patient-years of etanercept exposure [31]. Neither demyelinization nor new cases of uveitis were reported during 312 patient-years of etanercept use in 146 JIA 
patients in a Dutch JIA biological registry [32]. However, in that study two patients were diagnosed with sarcoidosis when receiving etanercept treatment, although this disease might be hard to differentiate from JIA when arthritis is the main feature, so it could be that this was the underlying diagnosis all the time [32]. In a German JIA biologic registry, 0.96 flare-ups of uveitis per 100 patient-exposure years were reported in 604 etanerceptusing JIA patients (11 incidents in 1,149 patient-exposure years) [33]. Optic nerve papillitis was confirmed in 0.17 per 100 patient-years ( 2 cases) and another patient experienced diminished color discrimination possibly indicative of retrobulbar neuritis [33]. Another German study found 1.7 new-onset autoimmune events per 100 patient-years in 346 JIA patients who used etanercept during the observation period, comprising 10 events in 598 patient-years: 2 new manifestations of IBD (also included in [70]), 2 new psoriasis cases, 4 new uveitis cases, one de novo systemic lupus erythematosus and one case of neuromyelitis nervi optici were reported [34].

In a prospective study, 14 patients were followed for 2 years after the start of etanercept for JIA in order to register newly developed autoantibodies and their clinical significance [71]. During etanercept treatment administration, 5 out of 14 patients developed new autoantibodies (4 patients with anti-reticulin antibodies and one with anti-thyroid peroxidase antibodies), which persisted for 12 to 50 months. Only the patient with the antithyroid peroxidase antibodies developed clinical symptoms, which was a goiter (because of Hashimoto's thyroiditis) 9 months after initiation of etanercept treatment and 6 months after the development of the antithyroid peroxidase antibodies [71].

\section{Infliximab}

New-onset uveitis was reported in 5.1 cases per 100 exposure-years during one year of the open-label extension phase of infliximab (4 cases in 78 patients) [36]. Newly positive antinuclear antibodies ( $\geq 1: 320)$ occurred in 25.9 cases per 100 exposure-years and anti-double stranded DNA in 6.6 cases per 100 exposure-years of patients during 58 to 61 exposure years of infliximab in JIA patients [36]. No patient exhibited clinical signs or symptoms suggesting lupus or lupus-like syndrome. During a prospective study with 2-year follow-up of newly developed autoantibodies after the start of infliximab, only 1 of 12 JIA patients developed anti-smooth muscle antibodies at a low titer (1:80), which lasted 12 months but did not involve any relevant clinical entity [71].

\section{Tocilizumab}

In one study, 1 of 112 SJIA patients developed chronic panniculitis and had to discontinue tocilizumab [39]. None of the 17 polyarticular JIA patients had persistent elevation in autoantibodies (including antinuclear and anti-DNA antibodies) and no signs or symptoms of any other autoimmune disease were seen during 16 exposure years [40].

\section{Anti-drug antibody-formation}

Immunogenicity against therapeutic monoclonal antibodies (especially against infliximab and adalimumab) has been shown to be clinically important: it is associated with shorter response duration because of diminishing concentrations in the blood and with infusion reactions [72]. Concomitant immunomodulators in the form of MTX or azathioprine reduced the immunogenicity of therapeutic antibodies in RA, Crohn's disease, and juvenile idiopathic arthritis [72]. The occurrence of adverse events does not increase when immunomodulators are added to therapeutic antibodies. The mechanism whereby MTX and azathioprine influence immunogenicity remains unclear [72].

\section{Abatacept}

Twenty-three percent of JIA patients (44 of 189) using abatacept were seropositive at least once for antiabatacept or anti-CTLA-4 antibodies; 59\% (26 of 44) of these patients were positive only once [57]. In no case did seropositivity correlate with a clinical finding such as an adverse event, infusion reaction, or inefficacy [57].

\section{Anakinra}

Just one study mentions development of anti-IL-1ra antibodies in 86 polyarticular course JIA patients (only $17 \%$ with SJIA) using anakinra during 3 months followed by a 4-month placebo-controlled phase and afterwards a 12-month open-label extension phase [73]. In the first 3 months $75 \%$ of all patients were positive for nonneutralizing anti-IL-1ra antibodies and $6 \%$ had neutralizing antibodies. In the blinded phase $44 \%$ of placebotreated patients and $72 \%$ of anakinra-treated patients were positive for antibodies, with only one patient (in the placebo group) positive for neutralizing antibodies. In the extension study, $82 \%$ had confirmed presence of antiIL-1ra antibodies but none tested positive for neutralizing antibodies [73].

\section{Adalimumab}

At least one positive test for anti-adalimumab antibody was found in 16\% (27 of 171) of JIA patients during the 16-week open-label phase and following the 32-week double-blind phase [28]. Among the concomitant MTX users this was only $6 \%$, while it was $26 \%$ in patients not receiving MTX [28]. Development of anti-adalimumab antibody did not lead to a greater rate of discontinuation of the study drug, nor did it increase the incidence of serious adverse events [28]. Another study showed that at 
least one anti-adalimumab-positive serum sample was found in $15 \%$ of patients concomitantly using MTX (3 of 20) at both week 24 and week 60 , but for patients using adalimumab and not using MTX this was 20\% (1 of 5) at week 24 and increased to even $60 \%$ ( 3 of 5) at week 60 [30]. Trough concentrations of adalimumab below $2 \mu \mathrm{g} /$ $\mathrm{ml}$ were seen in three of the four patients in whom the anti-adalimumab-antibodies were detected at week 24, but were transient only [30].

\section{Etanercept}

Two of 68 (2.9\%) JIA patients tested positive for nonneutralizing antibodies against etanercept in a randomized controlled trial for etanercept in polyarticular JIA during 7 months [74].

\section{Infliximab}

Antibodies to infliximab were detected in 37\% (26 of 71) of JIA patients and in $31 \%$ the test was negative while $32 \%$ had an inconclusive status during the open-label extension phase of a randomized controlled trial [36]. At least one infusion-related reaction was seen in 32\% (25 of 78 ) of treated patients, with a higher occurrence (58\%) among patients classified as positive for antibodies to infliximab. One antibody-positive patient even had a possible anaphylactic reaction. There were no delayed hypersensitivity reactions [36].

\section{Tocilizumab}

In one study, 7.1\% (4 of 56) of SJIA patients followed for 0.9 years developed anti-tocilizumab IgE antibodies [38]. One anaphylactoid reaction was seen in a patient who tested negative for IgE-type anti-tocilizumab antibodies and previously had had allergic reactions to aspirin and infliximab [38]. Another study found that 1.8\% (2 of 112) of the SJIA patients developed anti-tocilizumab antibodies [39]. One patient experienced an anaphylactic reaction of life-threatening angioedema during the week 8 infusion. This event was preceded by urticaria directly after the week 4 infusion, which required treatment with intravenous corticosteroids. The second patient received partial infusions at weeks 4 and 6 because of infusion reaction-like symptoms such as back pain, shortness of breath, and changes in blood pressure. To manage the symptoms the infusions were stopped, and the patient was administered paracetamol [39].

\section{Future perspectives}

To date, it is hard to make clear statements on the incidence of adverse events that can be attributed to specific drugs in JIA patients. A lot can be learned about the role of medication in JIA complicated by serious events, as has been shown recently in a selected group of SJIA patients who developed pulmonary artery hypertension, interstitial lung disease and alveolar proteinosis [75]. These three conditions are under-recognized complications of sJIA that are frequently fatal. They may be the result of severe uncontrolled systemic disease activity, and may be influenced by medication exposure [75].

Unfortunately every study uses different definitions of adverse events (for example, serious infections defined as requiring antibiotics versus requiring hospitalization) and in many studies it is difficult to extract the exposureyears to a specific drug since only duration of follow-up of patients is mentioned. International post-marketing surveillance will be necessary to adequately address safety signals that might be encountered after prolonged exposure. Furthermore, the consequences of the use of sequential multiple biologicals in the same patient (switching) and even combination therapy of biologicals, as has been described in SJIA for anakinra and abatacept [76], are largely unknown. Since it became clear that spontaneous reporting and separate (national) cohorts do not have enough power to address important questions about potential adverse events of this fast growing list of new drugs, an international initiative called Pharmachild was started with funding from the European Union (FP7 grantno.260353). This is a uniform webbased register that will provide better insight into the real immunological consequences of separate drugs used in JIA. This register has been set up to uniformly register twice yearly clinical data such as medication use (including switches and concomitant medication), disease subtype, disease severity, and standardized MedDRAcoded (moderate to serious) adverse events as well as events of specific interest such as malignancies, serious infections, TB, IBD, systemic lupus erythematosus and demyelination. This will allow early detection, assessment and understanding of long- and short-term side effects of the use of biologics and will support regulatory decisions on marketing authorizations for these products. The European Network of Centres for Pharmacoepidemiology and Pharmacovigilance (ENCePP) has been created by the European Medicines Agency with a view to strengthening the available expertise and resources in Europe in the area of pharmacoepidemiology and pharmacovigilance. Its goal is to further strengthen the post-authorization monitoring of medicinal products in Europe by facilitating the conduct of multi-center, independent, post-authorization studies across Europe. A key element of ENCePP is to uphold high standards throughout the research process based on the principles of transparency and scientific independence. The ENCePP Seal has been awarded to the Pharmachild register.

\section{Conclusion}

Multiple biological response modifiers are used for treatment of JIA patients. Many of these drugs are not 
registered for this indication and uniform, international, post-marketing surveillance will be the only way to collect good quality safety data since JIA comprises a relatively small group of patients. The immunological consequences of the long-term use of biologicals differ per agent and are highly dependent on concomitant medication. Infection risk is mainly associated with JIA itself and moderate to high doses of steroids and not the use of a biological, although tocilizumab might be an exception to this rule. Malignancies do not seem to occur more in JIA patients using anti-TNF therapy, although the background rate of JIA patients might be higher than that of the general population. Generally, the immunogenicity of vaccines is good in JIA patients, but one should be cautious when administering new live attenuated vaccines in patients with high dose immunosuppressants, including biologicals. There is an increased incidence of demyelinating diseases, IBD and development of mostly clinically irrelevant auto-immune antibodies in JIA patients on anti-TNF. The occurrence of uveitis does not seem to be increased in patients with etanercept or abatacept. Anti-drug antibody formation is seen in many patients with monoclonal antibodies, especially when they do not use concomitant MTX, but these antibodies are mostly not correlated to clinical events.

This article is part of the series on Childhood rheumatic diseases, edited by Patricia Woo. Other articles in this series can be found at http://arthritis-research.com/series/childhood

\section{Abbreviations}

ADHD, attention deficit hyperactivity disorder; BCG, bacillus Calmette-Guerin; $\mathrm{Cl}$, confidence interval; DMARD, disease-modifying anti-rheumatic drug; ENCePP, European Network of Centres for Pharmacoepidemiology and Pharmacovigilance; FDA, Food and Drug Administration; GMT, geometric mean titer; IBD, inflammatory bowel disease; IGRA, interferon gamma enzymelinked immunosorbent assay; IL, interleukin; JIA, juvenile idiopathic arthritis; LTBI, latent tuberculosis infection; MMR, measles, mumps and rubella; mTNF, membrane bound TNF; MTX, methotrexate; PML, progressive multifocal leukoencephalopathy; RA, rheumatoid arthritis; SIR, standardized incidence ratio; SJIA, systemic onset juvenile idiopathic arthritis; TB, tuberculosis; TNF, tumor necrosis factor; TST, tuberculin skin test.

\section{Competing interests}

The authors declare that they have no competing interests.

\section{Acknowledgements}

The research leading to these results has received funding from the European Union's Seventh Framework Programme (FP7/2007-2013) under grant agreement $n^{\circ} 260353$ 'Pharmachild'.

Published: 24 May 2013

\section{References}

1. Ravelli A, Martini A: Juvenile idiopathic arthritis. Lancet 2007, 369:767-778.

2. Petty RE, Southwood TR, Manners P, Baum J, Glass DN, Goldenberg J, He X, Maldonado-Cocco J, Orozco-Alcala J, Prieur AM, Suarez-Almazor ME, Woo P; International League of Associations for Rheumatology: International League of Associations for Rheumatology classification of juvenile idiopathic arthritis: second revision, Edmonton, 2001. J Rheumatol 2004, 31:390-392.
3. Pascual V, Allantaz F, Arce E, Punaro M, Banchereau J: Role of interleukin-1 (IL-1) in the pathogenesis of systemic onset juvenile idiopathic arthritis and clinical response to IL-1 blockade. J Exp Med 2005, 201:1479-1486.

4. Ruperto N, Martini A: Current medical treatments for juvenile idiopathic arthritis. Front Pharmacol 2011, 2:60.

5. Beukelman T, Patkar NM, Saag KG, Tolleson-Rinehart S, Cron RQ, DeWitt EM, Ilowite NT, Kimura Y, Laxer RM, Lovell DJ, Martini A, Rabinovich CE, Ruperto N: 2011 American College of Rheumatology recommendations for the treatment of juvenile idiopathic arthritis: initiation and safety monitoring of therapeutic agents for the treatment of arthritis and systemic features. Arthritis Care Res (Hoboken) 2011, 63:465-482.

6. Ruperto N, Brunner HI, Quartier P, Constantin T, Wulffraat N, Horneff G, Brik R, McCann L, Kasapcopur O, Rutkowska-Sak L, Schneider R, Berkun Y, Calvo I, Erguven M, Goffin L, Hofer M, Kallinich T, Oliveira SK, Uziel Y, Viola S, Nistala K, Wouters C, Cimaz R, Ferrandiz MA, Flato B, Gamir ML, Kone-Paut I, Grom A, Magnusson B, Ozen S, et al:: Two randomized trials of canakinumab in systemic juvenile idiopathic arthritis. N Engl J Med 2012, 367:2396-2406.

7. Hashkes PJ, Uziel Y, Laxer RM: The safety profile of biologic therapies for juvenile idiopathic arthritis. Nat Rev Rheumatol 2010, 6:561-571.

8. Giannini EH, Lovell DJ, Silverman ED, Sundel RP, Tague BL, Ruperto N: Intravenous immunoglobulin in the treatment of polyarticular juvenile rheumatoid arthritis: a phase I/II study. Pediatric Rheumatology Collaborative Study Group. J Rheumatol 1996, 23:919-924.

9. Kaymakcalan Z, Sakorafas P, Bose S, Scesney S, Xiong L, Hanzatian DK, Salfeld J, Sasso EH: Comparisons of affinities, avidities, and complement activation of adalimumab, infliximab, and etanercept in binding to soluble and membrane tumor necrosis factor. Clin Immunol 2009, 131:308-316.

10. Scallon B, Cai A, Solowski N, Rosenberg A, Song XY, Shealy D, Wagner C: Binding and functional comparisons of two types of tumor necrosis factor antagonists. J Pharmacol Exp Ther 2002, 301:418-426.

11. Santora LC, Kaymakcalan Z, Sakorafas P, Krull IS, Grant K: Characterization of noncovalent complexes of recombinant human monoclonal antibody and antigen using cation exchange, size exclusion chromatography, and BIAcore. Anal Biochem 2001, 299:119-129.

12. Mitoma H, Horiuchi T, Tsukamoto H, Tamimoto Y, Kimoto $Y$, Uchino A, To K, Harashima S, Hatta N, Harada M: Mechanisms for cytotoxic effects of antitumor necrosis factor agents on transmembrane tumor necrosis factor alpha-expressing cells: comparison among infliximab, etanercept, and adalimumab. Arthritis Rheum 2008, 58:1248-1257.

13. Kleijwegt FS, Laban S, Duinkerken G, Joosten AM, Zaldumbide A, Nikolic T, Roep $\mathrm{BO}$ : Critical role for TNF in the induction of human antigen-specific regulatory T cells by tolerogenic dendritic cells. J Immunol 2010, 185:1412-1418.

14. Horneff G, Ebert A, Fitter S, Minden K, Foeldvari I, Kummerle-Deschner J, Thon A, Girschick HJ, Weller F, Huppertz HI: Safety and efficacy of once weekly etanercept $0.8 \mathrm{mg} / \mathrm{kg}$ in a multicentre 12 week trial in active polyarticular course juvenile idiopathic arthritis. Rheumatology (Oxford) 2009, 48:916-919.

15. Yim DS, Zhou H, Buckwalter M, Nestorov I, Peck CC, Lee H: Population pharmacokinetic analysis and simulation of the time-concentration profile of etanercept in pediatric patients with juvenile rheumatoid arthritis. J Clin Pharmacol 2005, 45:246-256.

16. Marodi L, Casanova JL: Primary immunodeficiencies may reveal potential infectious diseases associated with immune-targeting mAb treatments. J Allergy Clin Immunol 2010, 126:910-917.

17. Beukelman T, Xie F, Chen L, Baddley JW, Delzell E, Grijalva CG, Lewis JD, Ouellet-Hellstrom R, Patkar NM, Saag KG, Winthrop KL, Curtis JR; SABER Collaboration: Rates of hospitalized bacterial infection associated with juvenile idiopathic arthritis and its treatment. Arthritis Rheum 2012, 64:2773-2780.

18. Beukelman T, Xie F, Baddley JW, Chen L, Delzell E, Grijalva CG, Mannion ML, Patkar NM, Saag KG, Winthrop KL, Curtis JR; SABER Collaboration: Brief report: incidence of selected opportunistic infections among children with juvenile idiopathic arthritis. Arthritis Rheum 2013, 65:1384-1389.

19. Ruperto N, Lovell DJ, Quartier P, Paz E, Rubio-Pérez N, Silva CA, AbudMendoza C, Burgos-Vargas R, Gerloni V, Melo-Gomes JA, Saad-Magalhães C, Chavez-Corrales J, Huemer C, Kivitz A, Blanco FJ, Foeldvari I, Hofer M, Horneff G, Huppertz HI, Job-Deslandre C, Loy A, Minden K, Punaro M, Nunez AF, Sigal LH, Block AJ, Nys M, Martini A, Giannini EH; Paediatric Rheumatology International Trials Organization and the Pediatric Rheumatology Collaborative Study Group: Long-term safety and efficacy of abatacept in children with juvenile idiopathic arthritis. Arthritis Rheum 2010, 62:1792-1802. 
20. Nigrovic PA, Mannion M, Prince FH, Zeft A, Rabinovich CE, van Rossum MA, Cortis E, Pardeo M, Miettunen PM, Janow G, Birmingham J, Eggebeen A, Janssen E, Shulman Al, Son MB, Hong S, Jones K, llowite NT, Cron RQ, Higgins GC: Anakinra as first-line disease-modifying therapy in systemic juvenile idiopathic arthritis: report of forty-six patients from an international multicenter series. Arthritis Rheum 2011, 63:545-555.

21. Zeft A, Hollister R, LaFleur B, Sampath P, Soep J, McNally B, Kunkel G, Schlesinger M, Bohnsack J: Anakinra for systemic juvenile arthritis: the Rocky Mountain experience. J Clin Rheumatol 2009, 15:161-164.

22. Quartier P, Allantaz F, Cimaz R, Pillet P, Messiaen C, Bardin C, Bossuyt X, Boutten A, Bienvenu J, Duquesne A, Richer O, Chaussabel D, Mogenet A, Banchereau J, Treluyer JM, Landais P, Pascual V: A multicentre, randomised, double-blind, placebo-controlled trial with the interleukin-1 receptor antagonist anakinra in patients with systemic-onset juvenile idiopathic arthritis (ANAJIS trial). Ann Rheum Dis 2011, 70:747-754.

23. Swart JF, Barug D, Mohlmann M, Wulffraat NM: The efficacy and safety of interleukin-1-receptor antagonist anakinra in the treatment of systemic juvenile idiopathic arthritis. Expert Opin Bio/ Ther 2010, 10:1743-1752.

24. Alexeeva El, Valieva SI, Bzarova TM, Semikina EL, Isaeva KB, Lisitsyn AO, Denisova RV, Chistyakova EG: Efficacy and safety of repeat courses of rituximab treatment in patients with severe refractory juvenile idiopathic arthritis. Clin Rheumatol 2011, 30:1163-1172.

25. van Vollenhoven RF, Emery P, Bingham CO, III, Keystone EC, Fleischmann R, Furst DE, Macey K, Sweetser M, Kelman A, Rao R: Longterm safety of patients receiving rituximab in rheumatoid arthritis clinical trials. J Rheumatol 2010, 37:558-567.

26. Clifford DB, Ances B, Costello C, Rosen-Schmidt S, Andersson M, Parks D, Perry A, Yerra R, Schmidt R, Alvarez E, Tyler KL: Rituximab-associated progressive multifocal leukoencephalopathy in rheumatoid arthritis. Arch Neurol 2011 68:1156-1164

27. Molloy ES, Calabrese LH: Progressive multifocal leukoencephalopathy associated with immunosuppressive therapy in rheumatic diseases: evolving role of biologic therapies. Arthritis Rheum 2012, 64:3043-3051.

28. Lovell DJ, Ruperto N, Goodman S, Reiff A, Jung L, Jarosova K, Nemcova D, Mouy R, Sandborg C, Bohnsack J, Elewaut D, Foeldvari I, Gerloni V, Rovensky J, Minden K, Vehe RK, Weiner LW, Horneff G, Huppertz HI, Olson NY, Medich JR, CarcereriDe-Prati R, Mcllraith MJ, Giannini EH, Martini A; Pediatric Rheumatology Collaborative Study Group; Pediatric Rheumatology International Trials Organisation: Adalimumab with or without methotrexate in juvenile rheumatoid arthritis. NEngl J Med 2008, 359:810-820.

29. Trachana M, Pratsidou-Gertsi P, Pardalos G, Kozeis N, Badouraki M, KanakoudiTsakalidou F: Safety and efficacy of adalimumab treatment in Greek children with juvenile idiopathic arthritis. Scand J Rheumato/ 2011, 40:101-107.

30. Imagawa T, Takei S, Umebayashi H, Yamaguchi K, Itoh Y, Kawai T, I wata N, Murata T, Okafuji I, Miyoshi M, Onoe Y, Kawano Y, Kinjo N, Mori M, Mozaffarian N, Kupper H, Santra S, Patel G, Kawai S, Yokota S: Efficacy, pharmacokinetics, and safety of adalimumab in pediatric patients with juvenile idiopathic arthritis in Japan. Clin Rheumatol 2012, 31:1713-1721.

31. Lovell DJ, Reiff A, llowite NT, Wallace CA, Chon Y, Lin SL, Baumgartner SW, Giannini EH: Safety and efficacy of up to eight years of continuous etanercept therapy in patients with juvenile rheumatoid arthritis. Arthritis Rheum 2008, 58:1496-1504.

32. Prince FH, Twilt M, Ten CR, van Rossum MA, Armbrust W, Hoppenreijs EP, van Santen-Hoeufft M, Koopman-Keemink Y, Wulffraat NM, van Suijlekom-Smit LW: Long-term follow-up on effectiveness and safety of etanercept in juvenile idiopathic arthritis: the Dutch national register. Ann Rheum Dis 2009, 68:635-641.

33. Horneff G, De BF, Foeldvari I, Girschick HJ, Michels H, Moebius D, Schmeling H: Safety and efficacy of combination of etanercept and methotrexate compared to treatment with etanercept only in patients with juvenile idiopathic arthritis (JIA): preliminary data from the German JIA Registry. Ann Rheum Dis 2009, 68:519-525.

34. Minden K, Niewerth M, Zink A, Seipelt E, Foeldvari I, Girschick H, Ganser G, Horneff G: Long-term outcome of patients with JIA treated with etanercept, results of the biologic register JuMBO. Rheumatology (Oxford) 2012, 51:1407-1415.

35. Southwood TR, Foster HE, Davidson JE, Hyrich KL, Cotter CB, Wedderburn LR, Hull RG, Venning HE, Rahman JK, Cummins CL: Duration of etanercept treatment and reasons for discontinuation in a cohort of juvenile idiopathic arthritis patients. Rheumatology (Oxford) 2011, 50:189-195.
36. Ruperto N, Lovell DJ, Cuttica R, Woo P, Meiorin S, Wouters C, Silverman ED, Balogh Z, Henrickson M, Davidson J, Foeldvari I, Imundo L, Simonini G, Oppermann J, Xu S, Shen YK, Visvanathan S, Fasanmade A, Mendelsohn A, Martini A, Giannini EH; Paediatric Rheumatology INternational Trials Organization (PRINTO); Pediatric Rheumatology Collaborative Study Group (PRCSG): Long-term efficacy and safety of infliximab plus methotrexate for the treatment of polyarticular-course juvenile rheumatoid arthritis: findings from an open-label treatment extension. Ann Rheum Dis 2010, 69:718-722.

37. Tynjala P, Vahasalo P, Tarkiainen M, Kroger L, Aalto K, Malin M, Putto-Laurila A, Honkanen $\mathrm{V}$, Lahdenne P: Aggressive combination drug therapy in very early polyarticular juvenile idiopathic arthritis (ACUTE-JIA): a multicentre randomised open-label clinical trial. Ann Rheum Dis 2011, 70:1605-1612.

38. Yokota S, Imagawa T, Mori M, Miyamae T, Aihara Y, Takei S, Iwata N, Umebayashi H, Murata T, Miyoshi M, Tomiita M, Nishimoto N, Kishimoto T: Efficacy and safety of tocilizumab in patients with systemic-onset juvenile idiopathic arthritis: a randomised, double-blind, placebo-controlled, withdrawal phase III trial. Lancet 2008, 371:998-1006.

39. De Benedetti F, Brunner HI, Ruperto N, Kenwright A, Wright S, Calvo I, Cuttica R, Ravelli A, Schneider R, Woo P, Wouters C, Xavier R, Zemel L, Baildam E, Burgos-Vargas R, Dolezalova P, Garay SM, Merino R, Joos R, Grom A, Wulffraat N, Zuber Z, Zulian F, Lovell D, Martini A; PRINTO; PRCSG: Randomized trial of tocilizumab in systemic juvenile idiopathic arthritis. N Engl J Med 2012, 367:2385-2395.

40. Imagawa T, Yokota S, Mori M, Miyamae T, Takei S, Imanaka H, Nerome Y, Iwata N, Murata T, Miyoshi M, Nishimoto N, Kishimoto T: Safety and efficacy of tocilizumab, an anti-IL-6-receptor monoclonal antibody, in patients with polyarticular-course juvenile idiopathic arthritis. Mod Rheumatol 2012, 22:109-115.

41. Schiff MH, Kremer JM, Jahreis A, Vernon E, Isaacs JD, van Vollenhoven RF: Integrated safety in tocilizumab clinical trials. Arthritis Res Ther 2011, 13:R141.

42. Keane J, Gershon S, Wise RP, Mirabile-Levens E, Kasznica J, Schwieterman WD, Siegel JN, Braun MM: Tuberculosis associated with infliximab, a tumor necrosis factor alpha-neutralizing agent. N Eng/ J Med 2001, 345:1098-1104

43. Armbrust W, Kamphuis SS, Wolfs TW, Fiselier TJ, Nikkels PG, Kuis W, Wulffraat NM: Tuberculosis in a nine-year-old girl treated with infliximab for systemic juvenile idiopathic arthritis. Rheumatology (Oxford) 2004, 43:527-529.

44. Kiray E, Kasapcopur O, Bas V, Kamburoglu-Goksel A, Midilli K, Arisoy N, Tastan $Y$ : Purified protein derivative response in juvenile idiopathic arthritis. J Rheumato/ 2009, 36:2029-2032.

45. Camlar SA, Makay B, Appak O, Appak YC, Esen N, Gunay T, Anal O, Unsal E: Performance of tuberculin skin test and interferon gamma assay for the diagnosis of latent tuberculosis infection in juvenile idiopathic arthritis. Clin Rheumato/ 2011, 30:1189-1193.

46. Hatemi G, Melikoglu M, Ozbakir F, Tascilar K, Yazici H: Quantiferon-TB Gold in tube assay for the screening of tuberculosis before and during treatment with tumor necrosis factor alpha antagonists. Arthritis Res Ther 2012, 14:R147

47. Singh JA, Furst DE, Bharat A, Curtis JR, Kavanaugh AF, Kremer JM, Moreland LW, O'Dell J, Winthrop KL, Beukelman T, Bridges SL Jr, Chatham WW, Paulus HE, Suarez-Almazor M, Bombardier C, Dougados M, Khanna D, King CM, Leong AL, Matteson EL, Schousboe JT, Moynihan E, Kolba KS, Jain A, Volkmann ER, Agrawal H, Bae S, Mudano AS, Patkar NM, Saag KG: 2012 update of the 2008 American College of Rheumatology recommendations for the use of disease-modifying antirheumatic drugs and biologic agents in the treatment of rheumatoid arthritis. Arthritis Care Res (Hoboken) 2012, 64:625-639.

48. Furst DE, Keystone EC, Braun J, Breedveld FC, Burmester GR, De Benedetti F, Dörner T, Emery P, Fleischmann R, Gibofsky A, Kalden JR, Kavanaugh A, Kirkham B, Mease P, Sieper J, Singer NG, Smolen JS, Van Riel PL, Weisman MH, Winthrop $\mathrm{K}$ : Updated consensus statement on biological agents for the treatment of rheumatic diseases, 2011. Ann Rheum Dis 2012, 71 Suppl 2:i2-45.

49. Ruperto N, Lovell DJ, Cuttica R, Wilkinson N, Woo P, Espada G, Wouters C, Silverman ED, Balogh Z, Henrickson M, Apaz MT, Baildam E, Fasth A, Gerloni V, Lahdenne P, Prieur AM, Ravelli A, Saurenmann RK, Gamir ML, Wulffraat N, Marodi L, Petty RE, Joos R, Zulian F, McCurdy D, Myones BL, Nagy K, Reuman P, Szer I, Travers S, et al:: A randomized, placebo-controlled trial of infliximab plus methotrexate for the treatment of polyarticular-course juvenile rheumatoid arthritis. Arthritis Rheum 2007, 56:3096-3106.

50. US Food and Drug Administration MedWatch: Questions and answers - TNF blockers [http://www.fda.gov/Drugs/DrugSafety/ 
PostmarketDrugSafetyInformationforPatientsandProviders/Drug SafetylnformationforHeathcareProfessionals/ucm180694.htm]

51. US Food and Drug Administration MedWatch: Information for Healthcare Professionals: Tumor Necrosis Factor (TNF) Blockers (marketed as Remicade, Enbrel, Humira, Cimzia, and Simponi) [http://www.fda.gov/ Drugs/DrugSafety/PostmarketDrugSafety

InformationforPatientsandProviders/DrugSafetylnformationfor HeathcareProfessionals/ucm 174474.htm]

52. Horneff G, Foeldvari I, Minden K, Moebius D, Hospach T: Report on malignancies in the German juvenile idiopathic arthritis registry. Rheumatology (Oxford) 2011, 50:230-236.

53. Bernatsky S, Rosenberg AM, Oen KG, Duffy CM, Ramsey-Goldman R, Labrecque J, St PY, Clarke AE: Malignancies in juvenile idiopathic arthritis: a preliminary report. J Rheumatol 2011, 38:760-763.

54. Simard JF, Neovius M, Hagelberg S, Askling J: Juvenile idiopathic arthritis and risk of cancer: a nationwide cohort study. Arthritis Rheum 2010, 62:3776-3782

55. Truckenbrodt $\mathrm{H}$, Hafner R: Methotrexate therapy in juvenile rheumatoid arthritis: a retrospective study. Arthritis Rheum 1986, 29:801-807.

56. Beukelman T, Haynes K, Curtis JR, Xie F, Chen L, Bemrich-Stolz CJ, Delzell E, Saag KG, Solomon DH, Lewis JD: Rates of malignancy associated with juvenile idiopathic arthritis and its treatment. Arthritis Rheum 2012. 64:1263-1271

57. Ruperto N, Lovell DJ, Quartier P, Paz E, Rubio-Pérez N, Silva CA, AbudMendoza C, Burgos-Vargas R, Gerloni V, Melo-Gomes JA, Saad-Magalhães C, Sztajnbok F, Goldenstein-Schainberg C, Scheinberg M, Penades IC, Fischbach M, Orozco J, Hashkes PJ, Hom C, Jung L, Lepore L, Oliveira S, Wallace CA, Sigal LH, Block AJ, Covucci A, Martini A, Giannini EH; Paediatric Rheumatology INternational Trials Organization; Pediatric Rheumatology Collaborative Study Group: Abatacept in children with juvenile idiopathic arthritis: a randomised, double-blind, placebo-controlled withdrawal trial. Lancet 2008, 372:383-391.

58. Burmester GR, Panaccione R, Gordon KB, Mcllraith MJ, Lacerda AP: Adalimumab: long-term safety in 23458 patients from global clinical trials in rheumatoid arthritis, juvenile idiopathic arthritis, ankylosing spondylitis, psoriatic arthritis, psoriasis and Crohn's disease. Ann Rheum Dis 2013, 72:517-524.

59. McCroskery P, Wallace CA, Lovell DJ, Stryker S, Chernyukhin N, Blosch C, Zack DJ: Summary of worldwide pediatric malignancies reported after exposure to etanercept. Pediatr Rheumatol Online J 2010, 8:18.

60. Heijstek MW, Ott de Bruin LM, Bijl M, Borrow R, van der Klis F, Koné-Paut I, Fasth A, Minden K, Ravelli A, Abinun M, Pileggi GS, Borte M, Wulffraat NM; EULAR: EULAR recommendations for vaccination in paediatric patients with rheumatic diseases. Ann Rheum Dis 2011, 70:1704-1712.

61. Heijstek MW, Pileggi GC, Zonneveld-Huijssoon E, Armbrust W, Hoppenreijs EP, Uiterwaal CS, Kuis W, Wulffraat NM: Safety of measles, mumps and rubella vaccination in juvenile idiopathic arthritis. Ann Rheum Dis 2007, 66:1384-1387.

62. van Assen S, Holvast A, Benne CA, Posthumus MD, van Leeuwen MA, Voskuyl AE, Blom M, Risselada AP, de Haan A, Westra J, Kallenberg CG, Bijl M: Humoral responses after influenza vaccination are severely reduced in patients with rheumatoid arthritis treated with rituximab. Arthritis Rheum 2010, 62:75-81.

63. Looney RJ, Srinivasan R, Calabrese LH: The effects of rituximab on immunocompetency in patients with autoimmune disease. Arthritis Rheum 2008, 58:5-14

64. Borte S, Liebert UG, Borte M, Sack U: Efficacy of measles, mumps and rubella revaccination in children with juvenile idiopathic arthritis treated with methotrexate and etanercept. Rheumatology (Oxford) 2009, 48:144-148,

65. Farmaki E, Kanakoudi-Tsakalidou F, Spoulou V, Trachana M, Pratsidou-Gertsi P, Tritsoni M, Theodoridou M: The effect of anti-TNF treatment on the immunogenicity and safety of the 7-valent conjugate pneumococcal vaccine in children with juvenile idiopathic arthritis. Vaccine 2010, 28:5109-5113.

66. Dell'Era L, Corona F, Daleno C, Scala A, Principi N, Esposito S: Immunogenicity, safety and tolerability of MF59-adjuvanted seasonal influenza vaccine in children with juvenile idiopathic arthritis. Vaccine 2012, 30:936-940.

67. Aikawa NE, Campos LM, Goldenstein-Schainberg C, Saad CG, Ribeiro AC, Bueno C, Precioso AR, Timenetsky MC, Silva CA, Bonfa E: Effective seroconversion and safety following the pandemic influenza vaccination
(anti-H1N1) in patients with juvenile idiopathic arthritis. Scand J Rheumatol 2013, 42:34-40.

68. Shinoki T, Hara R, Kaneko U, Miyamae T, Imagawa T, Mori M, Yokota S: Safety and response to influenza vaccine in patients with systemic-onset juvenile idiopathic arthritis receiving tocilizumab. Mod Rheumatol 2012, 22:871-876.

69. Virta $\mathrm{L}$, Kolho $\mathrm{KL}$ : The risk of contracting pediatric inflammatory bowel disease in children with celiac disease, epilepsy, juvenile arthritis and type 1 diabetes--a nationwide study. J Crohns Colitis 2013, 7:53-57.

70. van Dijken TD, Vastert SJ, Gerloni VM, Pontikaki I, Linnemann K, Girschick H, Armbrust W, Minden K, Prince FH, Kokke FT, Nieuwenhuis EE, Horneff G, Wulffraat NM: Development of inflammatory bowel disease in patients with juvenile idiopathic arthritis treated with etanercept. J Rheumatol 2011, 38:1441-1446.

71. Kanakoudi-Tsakalidou F, Tzimouli V, Pratsidou-Gertsi P, Chronopoulou E, Trachana M: The significance of persistent newly developed autoantibodies in JIA patients under long-term anti-TNF treatment. Cytokine 2008, 42:293-297.

72. Krieckaert CL, Bartelds GM, Lems WF, Wolbink GJ: The effect of immunomodulators on the immunogenicity of TNF-blocking therapeutic monoclonal antibodies: a review. Arthritis Res Ther 2010, 12:217.

73. Ilowite N, Porras O, Reiff A, Rudge S, Punaro M, Martin A, Allen R, Harville T, Sun YN, Bevirt T, Aras G, Appleton B: Anakinra in the treatment of polyarticular-course juvenile rheumatoid arthritis: safety and preliminary efficacy results of a randomized multicenter study. Clin Rheumatol 2009, 28:129-137.

74. Lovell DJ, Giannini EH, Reiff A, Cawkwell GD, Silverman ED, Nocton JJ, Stein LD, Gedalia A, llowite NT, Wallace CA, Whitmore J, Finck BK: Etanercept in children with polyarticular juvenile rheumatoid arthritis. Pediatric Rheumatology Collaborative Study Group. N Engl J Med 2000, 342:763-769.

75. Kimura Y, Weiss JE, Haroldson KL, Lee T, Punaro M, Oliveira S, Rabinovich E, Riebschleger M, Antón J, Blier PR, Gerloni V, Hazen MM, Kessler E, Onel K, Passo MH, Rennebohm RM, Wallace CA, Woo P, Wulffraat N; Childhood Arthritis Rheumatology Research Alliance Carra Net Investigators: Pulmonary hypertension and other potentially fatal pulmonary complications in systemic juvenile idiopathic arthritis. Arthritis Care Res (Hoboken) 2012, 65:745-752.

76. Record JL, Beukelman T, Cron RQ: Combination therapy of abatacept and anakinra in children with refractory systemic juvenile idiopathic arthritis: a retrospective case series. J Rheumatol 2011, 38:180-181.

77. Gritz DC, Wong IG: Incidence and prevalence of uveitis in Northern California; the Northern California Epidemiology of Uveitis Study. Ophthalmology 2004, 111:491-500.

78. Sawczenko A, Sandhu BK, Logan RF, Jenkins H, Taylor CJ, Mian S, Lynn R: Prospective survey of childhood inflammatory bowel disease in the British Isles. Lancet 2001, 357:1093-1094.

79. Ketelslegers IA, Catsman-Berrevoets CE, Neuteboom RF, Boon M, van Dijk KG, Eikelenboom MJ, Gooskens RH, Niks EH, Overweg-Plandsoen WC, Peeters EA, Peeters-Scholte CM, Poll-The BT, de Rijk-van Andel JF, Samijn JP, Snoeck IN, Stroink H, Vermeulen RJ, Verrips A, Vles JS, Willemsen MA, Rodrigues Pereira R, Hintzen RQ: Incidence of acquired demyelinating syndromes of the CNS in Dutch children: a nationwide study. J Neurol 2012, 259:1929-1935.

80. Achiron A, Garty BZ, Menascu S, Magalashvili D, Dolev M, Ben-Zeev B, PinhasHamiel O: Multiple sclerosis in Israeli children: incidence, an clinical, cerebrospinal fluid and magnetic resonance imaging findings. Is $\mathrm{Med}$ Assoc J 2012, 14:234-239.

81. Bertilsson L, ndersson-Gare B, Fasth A, Forsblad-d'Elia H: A 5-year prospective population-based study of juvenile chronic arthritis: onset, disease process, and outcome. Scand J Rheumatol 2012, 41:379-382.

82. Saurenmann RK, Levin AV, Feldman BM, Laxer RM, Schneider R, Silverman ED Risk factors for development of uveitis differ between girls and boys with juvenile idiopathic arthritis. Arthritis Rheum 2010, 62:1824-1828.

83. Klein A, Kaul I, Foeldvari I, Ganser G, Urban A, Horneff G: Efficacy and safety of oral and parenteral methotrexate therapy in children with juvenile idiopathic arthritis: an observational study with patients from the German Methotrexate Registry. Arthritis Care Res (Hoboken) 2012, 64:1349-1356.

doi:10.1186/ar4213

Cite this article as: Swart JF, et al.: What are the immunological consequences of long-term use of biological therapies for juvenile idiopathic arthritis? Arthritis Research \& Therapy 2013, 15:213. 